\title{
Considerations on the physical and mechanical properties of lime-stabilized rammed earth walls and their evaluation by ultrasonic pulse velocity testing
}

Jacinto Canivell ${ }^{1, a}$, Juan Jesús Martin-del-Rio ${ }^{2, a,{ }^{*}}$, F. J. Alejandre ${ }^{3, a}$, Joaquín García-Heras ${ }^{4, b}$, Alberto Jimenez-Aguilar ${ }^{5, a}$

${ }^{a}$ Dpto. Construcciones Arquitectónicas II, Universidad de Sevilla, Av. Reina Mercedes 4, 41012 Sevilla, Spain.

${ }^{\mathrm{b}}$ Dpto. Estadística e Investigación Operativa, Universidad de Sevilla, c/Tarfia s/n, 41012 Sevilla, Spain.

1‥jacanivell@us.es, ${ }^{2}$ ijdelrio@us.es, ${ }^{3}$ falejan@us.es, ${ }^{4}$ heras@us.es, ${ }^{5}$ albertosevilla91@gmail.com

* Corresponding author.

\section{Abstract (max. 100 words)}

This study examines the influence of moulding moisture content on the compressive strength, dry density and porosity of a rammed earth wall, using ultrasound as a complementary technique. Non-parametric and multivariate statistical techniques were applied to analyse the behaviour of variables with a sufficiently large population. The statistical analysis demonstrated that excessive or insufficient moulding moisture content directly determines the physicalmechanical properties of such walls. Ultrasound was confirmed as a valid technique for assessing the quality of a wall, since its response, albeit with certain limitations, was consistent with physical-mechanical properties.

\section{Highlights}

- Moulding moisture content has a decisive influence on physical-mechanical properties.

- Non-parametric and multivariate statistical techniques were applied.

- Ultrasound can be used to qualitatively assess the quality of a rammed earth wall. 


\section{Keywords (max. 10 key words)}

Rammed earth, ultrasonic test, compressive strength, open porosity, dry density, nondestructive testing.

\section{Introduction}

The study of the mechanical properties of rammed earth (RE) currently presents many gaps in relation to aspects associated with standardization, test methodology and relationships with other properties of this material, such as open porosity and dry density. As far as standardization is concerned, although this subject has been researched in greater depth in some countries (Germany, France or New Zealand, among others), there is still a need to further develop the control of execution techniques and experimental tests to determine the quality of RE, otherwise the potential of this sustainable technique will not be fully exploited. In terms of the test methodologies, existing research focuses on studies of the mechanical strength of unstabilized RE walls $[1,2]$ or those stabilized mainly with cement, such as the walls described in the studies carried out by Jayasinghe and Kamaladasa [3], Kamaladasa and Jayasinghe [4], Ciancio and Gibbings [5] or Ciancio et al. [6], and only a few researchers have considered stabilization with lime, for example Ciancio et al. [6] or Da Rocha et al. [7], although this material is often used in the conservation of heritage buildings, since walls made with these materials are more compatible with existing support materials.

One of the most influential factors on the mechanical strength of RE walls is moulding moisture content (MMC), which is taken into account to determine the optimum moisture content (OM) of compaction, and is often determined by the normal [8] or modified Proctor compaction test. However, until now consideration has been given mainly to the moisture content of RE at the time of testing, which has been associated with the suction effect for unstabilized $\operatorname{RE}[9,10]$, or with mechanical compressive strength $[10,11]$. Therefore, although MMC directly affects dry 
density (D) and open porosity (P) in stabilized soils [10], other studies have not considered this variable for analysing the quality of RE walls in relation to their mechanical strength or physical parameters ( $D$ and $P$ ). It is also necessary to highlight the difficulty in maintaining MMC constant between different batches, either on site or in the laboratory, since this will depend on the mixing method used, soil composition or the presence of lime, among other factors, causing these variations to alter certain physical-mechanical characteristics of RE structures.

Ultrasonic pulse velocity is a well-known non-destructive test for assessing Young's modulus and inner cracks of concrete, metals or wooden materials. However, studies on RE are not abundant. To find studies on the application of this technique in walls, it was necessary to review research carried out on historic buildings, in which attempts have been made to correlate the results obtained using a sclerometer with wall unconfined compressive strength [12], or those carried out by Liang [13] using ultrasound, to obtain a better understanding of the thermo-mechanical and ageing responses of buildings under thermal loads and affected by earthquakes. GalánMarín et al. [14] used ultrasound to evaluate the retraction and adhesion of fibres in blocks of earth, and suggest that this technique may be used to evaluate mechanical characteristics. Mansour et al. [15] propose the use of low frequency waves to study certain physical properties of compressed earth blocks, with interesting results. Except for the recent study by Bernat-Maso et al. [16], who propose ultrasound to assess moisture content and determine Young's modulus, no studies have faithfully correlated the results of these types of non-destructive tests with the mechanical properties of RE walls, and much less so during their execution, in contrast to the situation for other types of materials such as concrete [17], mortar, etc. Furthermore, many studies do not statistically process the results to verify their reliability, either because of the small number of samples $[3,10,20-22]$ or because the authors decided to perform a descriptive analysis of the results $[5,6,23-25]$. 
The aim of this research was to use a statistics-based approach to analyse the relationships existing between different physical-mechanical properties (dry density, open porosity and compressive strength) and ultrasonic pulse velocity in a RE wall with an established dosage and compaction energy, prepared with different MMC, starting at optimum compaction humidity. Since this study was carried out within the context of a research project ${ }^{1}$, the construction materials used in restoration work therefore served as a reference to establish the basis of the analysis.

\section{Material and methods}

The RE used in this research consisted of a mixture of sand, calcareous soil (a biocalcarenite known locally as "albero"), sub-soil from the surrounding area and hydraulic lime HL5. The dosage in volume (5 sub-soil: 2 sand: 2 water: 2 lime) was the same as that used and corresponded approximately to a ratio of sand, gravel and silty clay of $5: 4: 1$, according to the coding system proposed by Hall [18].

Soil suitability was studied and assessed by means of on-site tests [25] (drop test, ribbon test, visual inspection, sedimentation) and laboratory tests: particle size distribution (Fig. 3) [26], plasticity limits $[27,28]$, X-ray powder diffraction (XRD) proposed for determining overall mineralogy (Fig. 4) for the aggregate mixture, organic matter content $[29,30]$ and optimum water content [8].

Since no Spanish standard regulating the elaboration of RE specimens is available, a procedure was developed in accordance with recommendations provided in international standards and manuals [31,32]. RE cube samples were used [18], although cylindrical shapes have been

\footnotetext{
${ }^{1}$ Project 68/83-2738 - Analysis of materials for the restoration of a rammed earth wall at the Alcazar (Fortess) of King Pedro, Camona, Seville. University of Seville.
} 
considered by other authors [6], as well as the UNE-EN concrete standard [33]. To obtain statistically representative results, 40 cube samples were gathered in 5 batches of 8 samples. Each batch comprised 4 moulds measuring $0.1 \times 0.1 \times 0.4 \mathrm{~m}$ (Fig. 1). First, four (4) prismatic samples per batch measuring $0.3 \mathrm{~m}$ in height were compacted. After 28-days' curing in laboratory conditions (temperatures of $18-22^{\circ} \mathrm{C}$ and $50-60 \%$ relative humidity), they were cut into two identical sections and then cut again into two pieces, leaving 2 cubes measuring $0.1 \mathrm{~m}$ on each side and two $0.05 \mathrm{~m}$-tall slices for each prismatic mould. According to the UNE-EN 12504-1 standard [33], the size of a cube specimen must comply with the ratio of 1:3 between the maximum aggregate size and the test specimen edge. Consequently, particles larger than $3.15 \mathrm{~cm}$ were discarded.

Samples were identified by a code according to the batch number (from 1 to 5), and their corresponding 8 cube specimens, as represented in Figure 1, i.e. sample 1.1 was the first cube specimen in the first batch.

To ensure the best match between the samples and real conditions, RE components were mixed in a steel drum concrete mixer and samples were compacted through manual ramming. Starting at an $\mathrm{OM}$ of $18.5 \%, 5$ steps were planned with $1 \%$ decreases in MMC until the value of $14.5 \%$ was reached (Table 1). The values above $18.5 \%$ hindered the execution of the test pieces due to excessive plasticity, since below $14.0 \%$ they prevented adequate mixing and compaction due to excessive dryness. OM and maximum D were determined by the Proctor compaction method [8]. Given the moisture of the dried earth, water was then added as a percentage of weight until the MMC established for each batch was achieved. The MMC of each batch was established as the average of 4 samples and determined in accordance with the UNE 103-300:93 standard $[34,35]$. To conserve initial soil moisture content, each batch was kept insulated inside a plastic bag before being mixed. 
Since manual ramming was employed, the Proctor compaction method was followed to establish the amount of compaction energy needed to ensure maximum $D$, as proposed by Ciancio and Gibbings [5] and Ciancio, Jaquin and Walker [6]. To that end, compaction energy per volume was controlled by the weight of the rammer $(3.3 \mathrm{~kg})$, in addition to the number of strokes and the free fall height of the rammer. The compaction energy per volume for manual ramming must correspond to the Proctor test. To achieve the same MMC for the specimens, they were cured for 28 days in the same environmental conditions ( $20^{\circ} \mathrm{C} \pm 2^{\circ} \mathrm{C}$ and $65 \pm 5 \%$ relative humidity), as proposed by Ciancio, Jaquin, and Walker [6], Hall and Djerbid [18], and as stipulated by Standard New Zealand [31] and mortar regulation UNE-EN 1015-11:2000 [36].

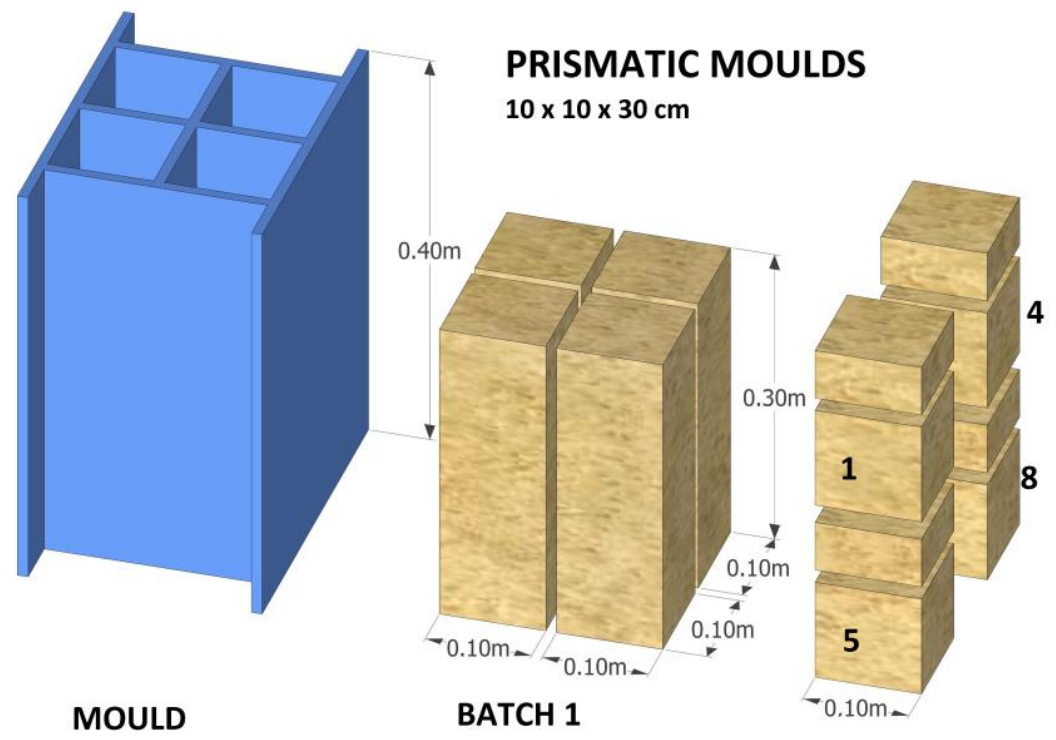

\section{CUBE SPECIMENS $10 \times 10 \times 5 \mathrm{~cm}$}

\section{SLICES}

$10 \times 10 \times 5 \mathrm{~cm}$

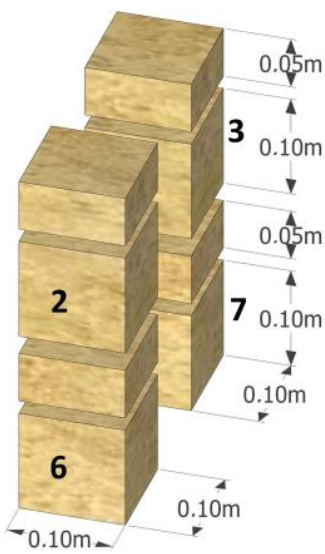

Fig. 1. Preparation of samples from prismatic shape moulds.

Once cured, $P$ and $D$ were obtained for the $5 \mathrm{~cm}$-tall slices by means of a water saturation method in a vacuum. To that end, dry, saturated and hydrostatic weights were established as provided in UNE-EN-1936 [37]. Ultrasonic tests were performed on 40 cube samples with an Ultrasonic-Tester BP-7 Series (UltraTest $\mathrm{GmbH}$ ), following the procedures established in the UNE-EN 12504-4 standard [38]. Three readings were recorded for each orientation so that each 
specimen was represented by three average measurements of ultrasonic pulse velocity (UPV), namely X-UPV, Y-UPV, and Z-UPV (Fig. 2), corresponding to the orientation of compaction. Due to the roughness of surfaces, modelling clay was used as a coupling for sensors.

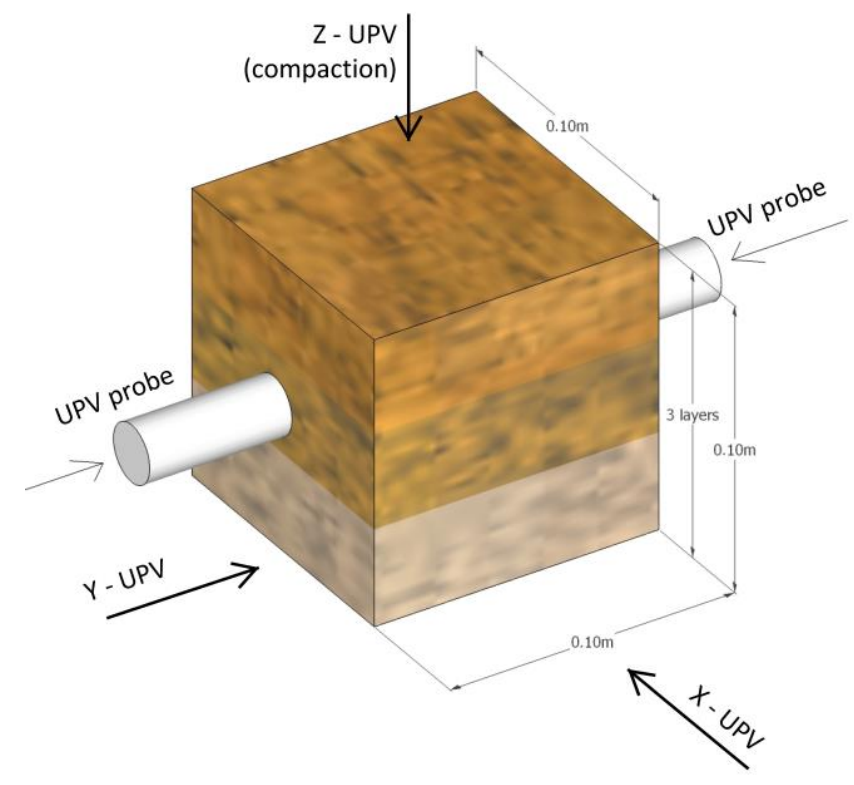

Fig. 2. Cube specimen of RE and orientations of the ultrasonic pulse test.

Unconfined compressive strength (CS) was determined at 28 days ageing using an electromechanical strength testing machine (TCCSL model PCI-30t) equipped with a 30-t load cell, with a loading rate of $330 \mathrm{~N} / \mathrm{s}$ and breaking times of 30-90 s, following the procedure described in the UNE-EN 1015-11 standard [36]. This value corresponds to the interval established for mortars at $5 \mathrm{~N} / \mathrm{s}$ to $500 \mathrm{~N} / \mathrm{s}$ and also proposed by Hall and Djerbib [18]. The same 40 specimens tested to determine UPV were capped with sulphur and tested in the orthogonal orientation of compaction layers to determine CS.

\section{Results}

\subsection{Results on raw materials (particle size distribution, Proctor, limits)}

Sub-soil and complete dosage employed (5 soil: 2 sand: 2 "albero": 2 lime) were analysed in terms of particle size distribution (PSD), as shown in Figure 3. The upper and lower limits 
corresponded to Hall and Djerbib [18] and should be taken as an approximate guide, since RE margins are usually rather wide. Nevertheless, the subsoil curve showed a certain deficiency in sand $(0.5$ to $0.25 \mathrm{~mm})$, which was corrected in the complete dosage although the silt-clay ratio $(>0.063 \mathrm{~mm})$ decreased to below the recommended limit. Fine particles are essential to provide mechanical strength in non-stabilized RE where water suction has been discussed as a source of cohesion [9]. However, when dealing with lime-stabilized RE, strength is provided by the increase in $\mathrm{D}$, enhancing particle interlocking and lime bonding.

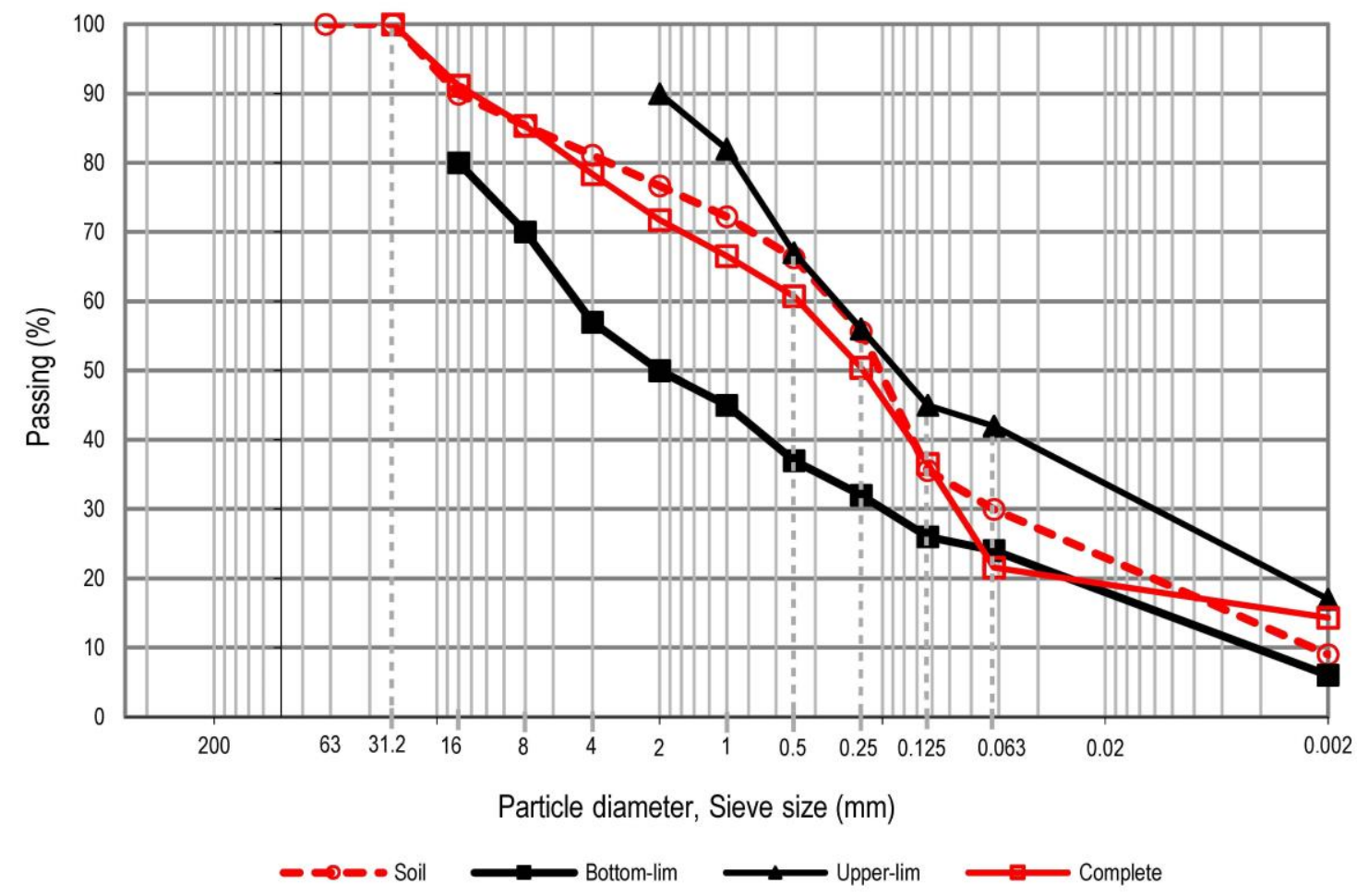

Fig. 3. Particle grading curves for sub-soil and complete dosage.

The mineral phases identified in the mixture of aggregates (Fig. 4) were as expected taking into account the nature of their components, calcite and quartz being the main minerals, together with mineral traces of clays (phyllosilicates), K-feldespars (microcline) and plagioclase (anorthite). 


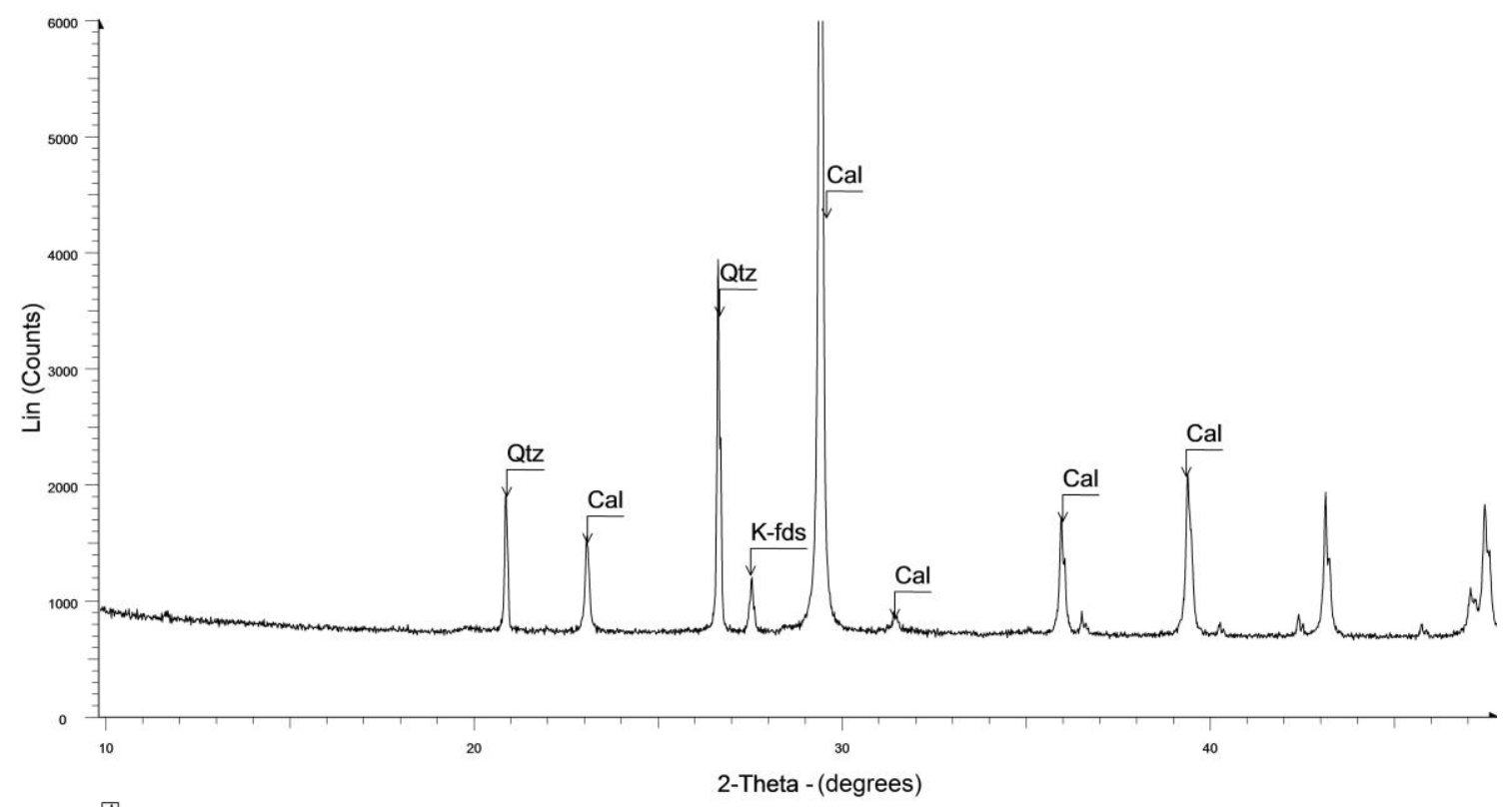

Fig. 4. XRD diagram for the determining overall mineralogy of the soil.

OM was established for the complete dosage in accordance with the UNE 103-500 standard [8] and is shown in Figure 5. OM is $18.25 \%$, corresponding to a $D$ of $1.63 \mathrm{~g} / \mathrm{cm}^{3}$. These values served as a reference to be followed during sample production. The 40 cube specimens were produced in several intervals, 5 batches for each group of 8 specimens were prepared and mixture moisture content was controlled to ensure it remained within the dry mixture-to-OM range, without exceeding OM. 


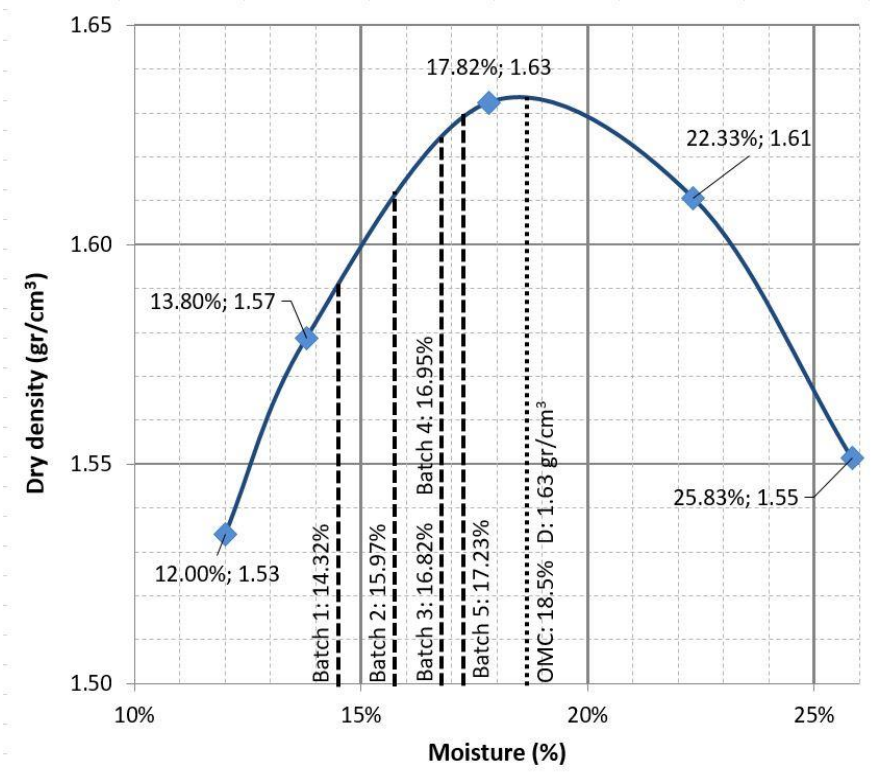

Fig. 5. OM for the complete dosage and MMC for all the batches.

\subsection{Moulding moisture content of the batches.}

The MMC of the batches are shown in Table 1. The data were ordered according to increasing moisture content (MMC1 to MMC5) up to values close to OM. It was not possible to take moisture values above OM since the soil quickly became plastic and this made it difficult to execute the specimens.

Table 1. MMC for all the batches.

\begin{tabular}{ccccccc}
\hline BATCH & & 1 & 2 & 3 & 4 & 5 \\
\hline Designed & $\mathrm{MMC}(\%)$ & $\mathrm{MMC1}$ & $\mathrm{MMC2}$ & $\mathrm{MMC3}$ & $\mathrm{MMC4}$ & $\mathrm{MMC5}$ \\
& & $14.50 \%$ & $15.50 \%$ & $16.50 \%$ & $17.50 \%$ & $18.50 \%$ \\
\hline \multirow{2}{*}{ Final } & $\mathrm{MMC}(\%)$ & $\mathrm{MMC1}$ & $\mathrm{MMC2}$ & $\mathrm{MMC3}$ & $\mathrm{MMC4}$ & $\mathrm{MMC5}$ \\
& & $14.32 \%$ & $15.97 \%$ & $16.82 \%$ & $16.95 \%$ & $17.23 \%$ \\
\hline
\end{tabular}

\subsection{Physical-mechanical properties (dry density, open porosity and strength)}

$\mathrm{P}$ and $\mathrm{D}$ are opposite parameters also related to the mechanical performance of stabilized RE as stated [39]. As expected, the lower the $D$, the higher the $P$ (Table 2). In relation to OM, a maximum $D$ of $1.63 \mathrm{~g} / \mathrm{cm}^{3}$ corresponds to a mean $\mathrm{P}$ of $38 \%$. The $\mathrm{P}$ values were therefore 
approximately the same as others for lime-stabilized RE [39] and corresponded to not very dense material with a considerable volume of pores compared with denser materials.

The CS values for the 40 specimens are shown in Table 2. All samples complied with the recommended CS as established in the NZS 4298 standard [31] and in Standards Australia [40]. Samples corresponding to MMC1 (14.32\%) showed the lowest CS values, which corresponded to the lowest measured percentage of water added during mixing. In fact, these samples had the highest $\mathrm{P}$ ratios. Therefore, given the same compaction energy applied, these soils did not reach similar densities.

Table 2. D, P and CS of the specimens and UPV for the RE specimens. X-UPV, Y-UPV, Z-UPV: UPV in X, Y and Z orientations.

\begin{tabular}{|c|c|c|c|c|c|c|c|c|c|c|c|c|c|c|c|c|}
\hline \multicolumn{9}{|c|}{ BATCH I } & \multicolumn{8}{|c|}{ BATCH II } \\
\hline Specimens & 1 & 2 & 3 & 4 & 5 & 6 & 7 & 8 & 9 & 10 & 11 & 12 & 13 & 14 & 15 & 16 \\
\hline $\mathrm{D}\left(\mathrm{gr} / \mathrm{cm}^{3}\right)$ & 1.56 & 1.57 & 1.57 & 1.55 & 1.58 & 1.58 & 1.56 & 1.57 & 1.54 & 1.55 & 1.56 & 1.54 & 1.58 & 1.56 & 1.60 & 1.59 \\
\hline $\mathrm{P}(\%)$ & 40.8 & 40.7 & 40.6 & 41.8 & 40.2 & 40.2 & 41.1 & 40.6 & 41.7 & 41.3 & 40.9 & 41.3 & 40.0 & 40.8 & 39.5 & 39.3 \\
\hline $\mathrm{CS}(\mathrm{MPa})$ & 1.37 & 1.83 & 1.67 & 1.13 & 1.62 & 1.58 & 1.42 & 1.62 & 2.30 & 2.03 & 1.98 & 2.22 & 1.70 & 2.88 & 2.71 & 2.96 \\
\hline$X-U P V(k m / s)$ & 1.27 & 1.4 & 1.31 & 1.32 & 1.31 & 1.33 & 1.26 & 1.34 & 1.58 & 1.52 & 1.57 & 1.63 & 1.64 & 1.78 & 1.63 & 1.71 \\
\hline $\mathrm{Y}-\mathrm{UPV}(\mathrm{km} / \mathrm{s})$ & 1.32 & 1.4 & 1.3 & 1.25 & 1.29 & 1.41 & 1.29 & 1.31 & 1.52 & 1.61 & 1.49 & 1.56 & 1.59 & 1.84 & 1.63 & 1.71 \\
\hline Z-UPV $(\mathrm{km} / \mathrm{s})$ & 1.41 & 1.32 & 1.48 & 1.43 & 1.42 & 1.43 & 1.32 & 1.25 & 1.49 & 1.58 & 1.59 & 1.62 & 1.51 & 1.7 & 1.54 & 1.66 \\
\hline \multicolumn{9}{|c|}{ BATCH III } & \multicolumn{7}{|c|}{ BATCH IV } & \\
\hline Specimens & 17 & 18 & 19 & 20 & 21 & 22 & 23 & 24 & 25 & 26 & 27 & 28 & 29 & 30 & 31 & 32 \\
\hline $\mathrm{D}\left(\mathrm{gr} / \mathrm{cm}^{3}\right)$ & 1.65 & 1.65 & 1.64 & 1.63 & 1.64 & 1.63 & 1.64 & 1.64 & 1.63 & 1.62 & 1.62 & 1.62 & 1.67 & 1.64 & 1.64 & 1.66 \\
\hline P (\%) & 37.4 & 37.1 & 37.4 & 37.8 & 37.7 & 38.0 & 37.5 & 37.5 & 38.6 & 38.8 & 38.9 & 38.7 & 36.6 & 37.2 & 37.6 & 36.3 \\
\hline $\mathrm{CS}$ (MPa) & 2.35 & 2.81 & 2.55 & 2.07 & 2.42 & 2.76 & 2.56 & 2.84 & 4.02 & 4.11 & 4.01 & 3.77 & 4.39 & 4.19 & 4.05 & 4.59 \\
\hline$X-U P V(k m / s)$ & 1.67 & 1.83 & 1.74 & 1.69 & 1.7 & 1.88 & 1.71 & 1.71 & 1.71 & 1.79 & 1.73 & 1.73 & 1.7 & 1.82 & 1.7 & 1.74 \\
\hline $\mathrm{Y}-\mathrm{UPV}(\mathrm{km} / \mathrm{s})$ & 1.69 & 1.8 & 1.68 & 1.63 & 1.62 & 1.69 & 1.64 & 1.82 & 1.67 & 1.72 & 1.82 & 1.81 & 1.67 & 1.87 & 1.73 & 1.79 \\
\hline Z-UPV $(\mathrm{km} / \mathrm{s})$ & 1.67 & 1.66 & 1.62 & 1.66 & 1.59 & 1.7 & 1.72 & 1.77 & 1.81 & 1.79 & 1.7 & 1.75 & 1.67 & 1.81 & 1.58 & 1.76 \\
\hline \multicolumn{9}{|c|}{ BATCH V } & & & & & & & & \\
\hline Specimens & 33 & 34 & 35 & 36 & 37 & 38 & 39 & 40 & & & & & & & & \\
\hline $\mathrm{D}\left(\mathrm{gr} / \mathrm{cm}^{3}\right)$ & 1.65 & 1.64 & 1.61 & 1.65 & 1.63 & 1.67 & 1.68 & 1.65 & & & & & & & & \\
\hline $\mathrm{P}(\%)$ & 38.0 & 38.2 & 39.2 & 37.8 & 38.5 & 37.0 & 36.8 & 37.6 & & & & & & & & \\
\hline $\mathrm{CS}$ (MPa) & 3.88 & 4.27 & 3.83 & 4.29 & 4.48 & 3.97 & 3.74 & 4.22 & & & & & & & & \\
\hline$X-U P V(k m / s)$ & 1.57 & 1.86 & 1.49 & 1.61 & 1.63 & 1.73 & 1.63 & 1.57 & & & & & & & & \\
\hline Y-UPV $(\mathrm{km} / \mathrm{s})$ & 1.57 & 1.61 & 1.45 & 1.64 & 1.72 & 1.62 & 1.66 & 1.62 & & & & & & & & \\
\hline Z-UPV(km/s) & 1.41 & 1.59 & 1.42 & 1.55 & 1.5 & 1.51 & 1.43 & 1.51 & & & & & & & & \\
\hline
\end{tabular}

\subsection{Ultrasonic pulse velocity}

After curing for 28 days, the 40 cube specimens were tested with the ultrasonic pulse device, as described for the methodology proposed in this research. Each sample was measured before testing the ultrasonic pulse velocity to determine its height, length and width (in $\mathrm{cm}$ ) and thus 
establish the UPV (cm/ $\mu \mathrm{s})$ for each orientation. UPV is represented in Table 2 for each orientation, with orientation $\mathrm{Z}$ corresponding to the direction of compaction. Table 2 presents the results for the 40 specimens, grouped into 8 samples, corresponding to each of the 5 batches.

\subsection{Statistical analysis}

Initially CS was to be represented according to the other variables (X-UPV, Y-UPV, Z-UPV, D, P) by means of a scattered chart to analyse their distribution. Figure 6 shows the groups of individuals presented according to batch moisture content (MMC1 to MMC5), suggesting that batch moisture content may have influenced the other variables. 

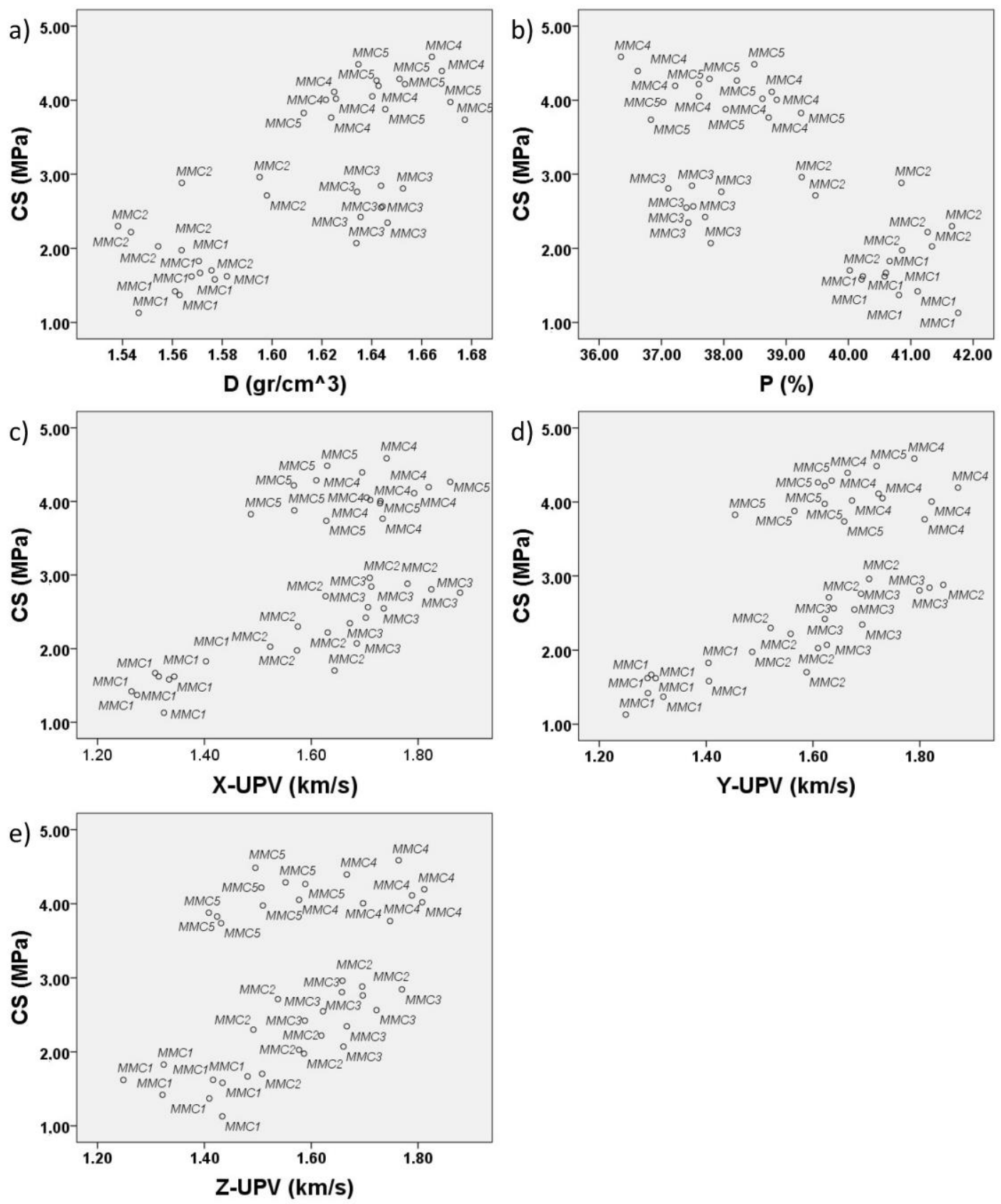

Fig. 6. Representation of CS according to the variables: a) CS vs P; b) CS vs D; c) CS vs X-UPV; d) CS vs Y-UPV; e) CS vs Z-UPV.

Given the suspicion that the behaviour of these variables may have differed depending on the $\mathrm{MMC}$ and since the number of individuals per batch was small (8 specimens), the Kruskal-Wallis non-parametric technique was chosen to determine whether the behaviour of each variable was the same for each MMC. The result obtained using this technique yielded a value of $p$-value $=0$ in each study (CS, UPV, D, P), thus confirming that each variable behaved differently from a mathematical standpoint depending on the MMC in each case. Consequently, the decision was 
taken to determine whether subgroups could be established according to moisture content for each variable. For this purpose, a multiple comparisons technique was applied. Tables 3 and 4 show the homogeneous subgroups that were formed for D, P and CS, which also corresponded to groups that maintained similar mixture moisture levels. The groupings for $D$ and $P$ were the same, with the lowest moisture levels (MMC1, MMC2) grouped in a separate subgroup from the highest moisture levels (MMC3, MMC4, MMC5). Although the situation with CS was similar with respect to the order of moisture levels, 3 homogeneous subgroups were proposed (MMC1, MMC2-3, MMC4-5), corresponding to the groupings shown in the diagrams in Fig. 7 for CS and MMC.

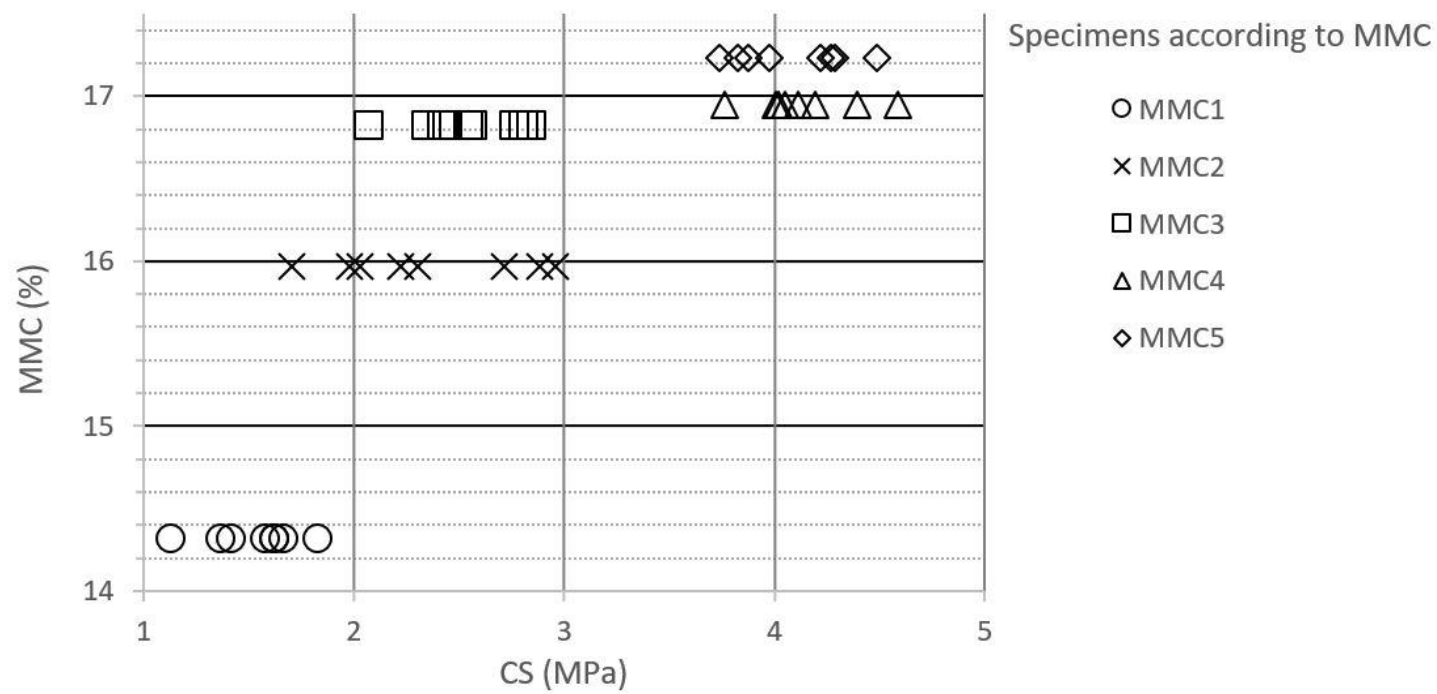

Fig. 7. CS plotted according to the MMC of each batch.

Table 3. Homogeneous subsets based on unconfined compressive strength (CS).

\begin{tabular}{cccc}
\hline & \multicolumn{3}{c}{ Subset according to CS } \\
\hline MMC & 1 & 2 & 3 \\
MMC1 & 4.625 & & \\
MMC2 & & 15.250 & 32.000 \\
MMC3 & & 17.625 & 33.000 \\
MMC5 & & 0.176 \\
Test statistic & --674 \\
Significance (test side 2) & -- & 0.893 & 0.940 \\
Adjusted sign. (test side 2) & -- & 0.652 & \\
Homogeneous subsets are based on asymptotic significances. The significance \\
level is 0.05.
\end{tabular}


The subgroups established for UPV differed somewhat although the extreme subsets always coincided with lowest moisture content (MMC1) and with one of the highest moisture contents (MMC4). Therefore, it may be stated that mixture moisture content had a decisive influence on the physical properties of the wall and that the homogeneous groupings corresponded to two sets: high MMC and low MMC.

Table 4. Homogeneous subsets based on $D$ and $P$

\begin{tabular}{|c|c|c|c|c|c|}
\hline \multicolumn{3}{|c|}{ Subset according to $\mathrm{D}$} & \multicolumn{3}{|c|}{ Subset according to $\mathrm{P}$} \\
\hline MMC & 1 & 2 & MMC & 1 & 2 \\
\hline MMC2 & 8.125 & & MMC3 & 10.375 & \\
\hline MMC1 & 8.875 & & MMC4 & 13.313 & \\
\hline MMC4 & & 25.875 & MMC5 & 13.813 & \\
\hline MMC3 & & 28.5 & MMC1 & & 32.375 \\
\hline MMC5 & & 31.125 & MMC2 & & 32.625 \\
\hline Test statistic & 0.099 & 2.206 & Test statistic & 1.104 & 0.011 \\
\hline Significance (test side 2 ) & 0.753 & 0.332 & Significance (test side 2 ) & 0.576 & 0.916 \\
\hline Adjusted sign. (test side 2 ) & 0.97 & 0.489 & Adjusted sign. (test side 2 ) & 0.760 & 0.998 \\
\hline \multicolumn{3}{|c|}{$\begin{array}{l}\text { Homogeneous subsets are based on asymptotic significances. } \\
\text { The significance level is } 0.05 \text {. }\end{array}$} & \multicolumn{3}{|c|}{$\begin{array}{c}\text { Homogeneous subsets are based on asymptotic significances. } \\
\text { The significance level is } 0.05 \text {. }\end{array}$} \\
\hline \multicolumn{3}{|c|}{ Each value for MMC1-5 corresponds to the average range of D. } & \multicolumn{3}{|c|}{ Each value for MMC1-5 corresponds to the average range of $P$} \\
\hline
\end{tabular}

Finally, all the properties were analysed together, without considering moisture, applying the multivariate Cluster-Analysis technique ( $\mathrm{k}$-means clustering method) applied to two groups. The aim was to define groups of specimens that formed clusters with a high degree of internal homogeneity. With the exception of one specimen (no. 8, batch 1), all the specimens with dry moisture levels (MMC1, MMC2 - batches 1 and 2) formed a cluster (cluster 1, low MMC), while the specimens with the highest moisture levels (MMC3, MMC4, MMC5 - batches 3, 4,5) were grouped in the other cluster (cluster 2, high MMC). These groupings may be characterized by the descriptive measurements shown in Table 5. It was verified that all the variables (X-UPV, YUPV, Z-UPV, D, P, CS) influenced these groupings, since the $p$-value was null for each group. Cluster 1 (low MMC) was characterized by having the lowest averages for all the properties (except $\mathrm{P}$, which responded inversely) when compared to cluster 2 .

Table. 5. Characteristic values of the clusters for each variable.

\begin{tabular}{cccc}
\hline & $\begin{array}{c}\text { Cluster 1 } \\
\text { (low MMC) }\end{array}$ & $\begin{array}{c}\text { Cluster 2 } \\
\text { (high MMC) }\end{array}$ & \% Dif (2-1) \\
\hline X-UPV (km/s) & 1.46 & 1.70 & 16.71 \\
Y-UPV (km/s) & 1.45 & 1.68 & 16.25 \\
Z-UPV $(\mathrm{km} / \mathrm{s})$ & 1.47 & 1.63 & 10.90 \\
CS (MPa) & 1.87 & 3.56 & 90.56 \\
D (gr/cm $\left.{ }^{3}\right)$ & 1.56 & 1.64 & 4.86 \\
P (\%) & 40.76 & 37.82 & -7.21 \\
\hline
\end{tabular}




\section{Discussion.}

The statistical analysis revealed that physical-mechanical parameters (D, P, CS) and the respective ultrasonic measurements of a lime-stabilized RE wall were closely involved with MMC and that it was also possible to form groups without taking into account MMC but coherent in their distribution. To discuss the results, the authors chose to establish the medians per batch of each parameter (Table 6), since this provides a better match than the average given the heterogeneity of the material and the dispersion of certain measurements. Moreover, since statistical analysis determined that groupings and clusters were consistent from the mathematical standpoint, the relationships among all the variables in terms of MMC must be strong.

Table. 6. The medians of the values of each batch expressed from left to right as a function of the increase in MMC.

\begin{tabular}{|c|c|c|c|c|c|c|}
\hline $\begin{array}{c}\text { Batch } \\
\text { MMC }(\%)\end{array}$ & $\begin{array}{c}1 \\
14.32 \\
\end{array}$ & $\begin{array}{c}2 \\
15.97\end{array}$ & $\begin{array}{c}3 \\
16.82 \\
\end{array}$ & $\begin{array}{c}4 \\
16.95 \\
\end{array}$ & $\begin{array}{c}5 \\
17.23 \\
\end{array}$ & \\
\hline & \multicolumn{2}{|c|}{$\begin{array}{l}\text { Low MMC } \\
\text { (Cluster 1) }\end{array}$} & \multicolumn{3}{|c|}{$\begin{array}{c}\text { High MMC } \\
\text { (Cluster 2) }\end{array}$} & $\begin{array}{l}\text { Relationships } \\
\text { between batches }\end{array}$ \\
\hline $\mathrm{D}\left(\mathrm{gr} / \mathrm{cm}^{3}\right)$ & 1.57 & 1.56 & 1.64 & 1.63 & 1.65 & $1 \leq 2<3 \leq 4 \leq 5$ \\
\hline $\mathrm{P}(\%)$ & 40.60 & 40.86 & 37.50 & 38.11 & 37.90 & $2 \geq 1>4 \geq 5 \geq 3$ \\
\hline $\mathrm{CS}(\mathrm{MPa})$ & 1.60 & 2.26 & 2.56 & 4.08 & 4.1 & $1<2<3<4 \leq 5$ \\
\hline X-UPV $(\mathrm{km} / \mathrm{s})$ & 1.32 & 1.63 & 1.71 & 1.73 & 1.62 & $1<5 \leq 2<3 \leq 4$ \\
\hline Y-UPV $(\mathrm{km} / \mathrm{s})$ & 1.30 & 1.60 & 1.68 & 1.76 & 1.62 & $1<2 \leq 5<3<4$ \\
\hline Z-UPV $(\mathrm{km} / \mathrm{s})$ & 1.41 & 1.58 & 1.66 & 1.75 & 1.51 & $1<5 \leq 2<3<4$ \\
\hline
\end{tabular}

Regarding the groupings shown in Table 6, the following aspects may be highlighted. Firstly, it can be observed that it was possible to group the specimens into low MMC (batches 1 and 2: 14.32\% and 15.97\%, respectively) and high MMC (batches 3, 4 and 5: 16.82\%, 16.95\% and 17.23\%, respectively), as discussed in the cluster analysis. As shown in Figures 8 and 9, this change in behaviour was also evidenced by the strong increase in $D$ and $P$ between batches 2 and 3. Figure 8 also shows that there is no direct relationship between $D$ and CS, as already discussed by Hall and Djerbib [18]. Considering the median D and P per batch, it was observed 
that these parameters clearly improved with the increase in median CS. This increase was more evident when considering the jump between low and high MMC batches.

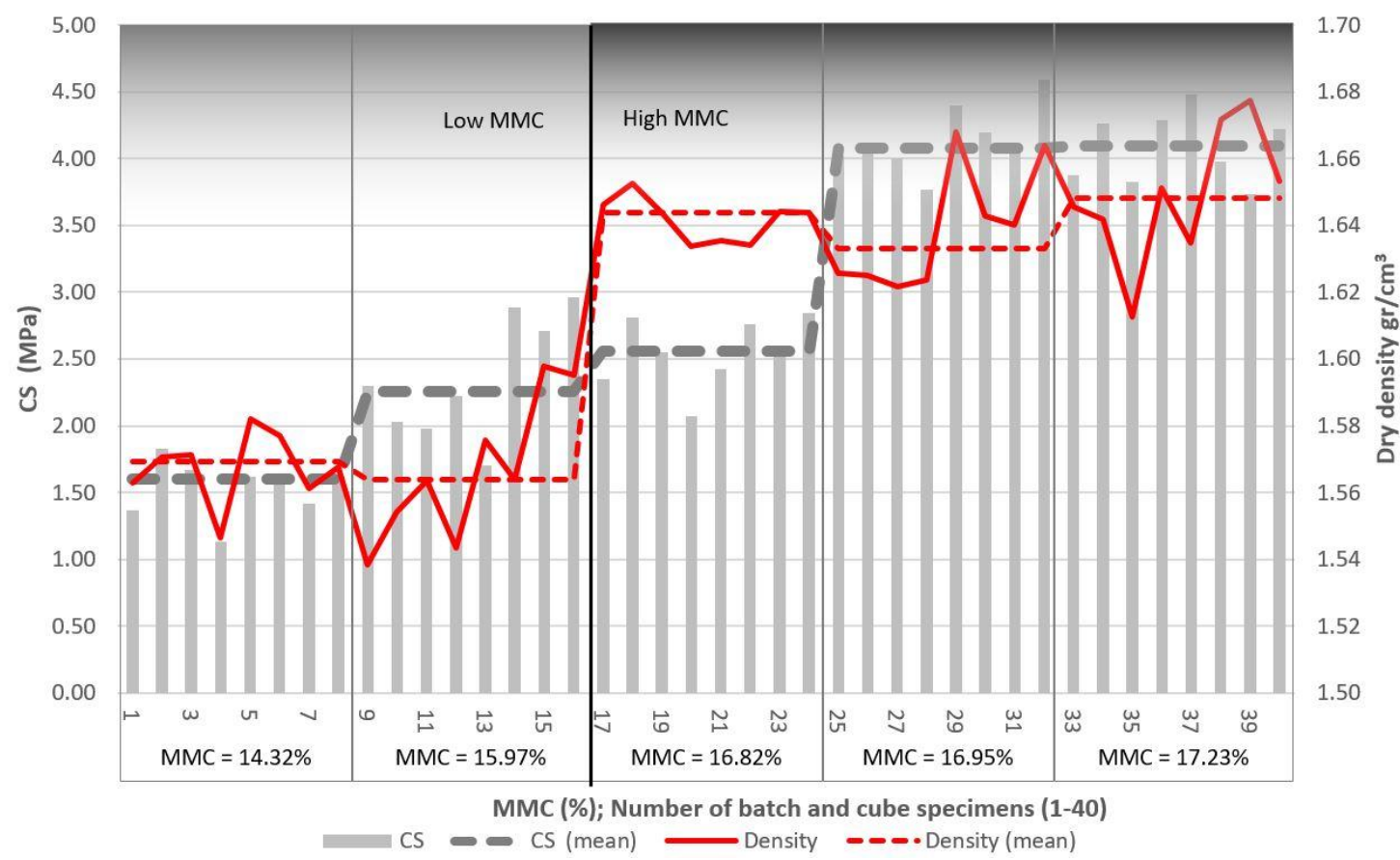

Fig. 8. Representation of $D$ according to batches and specimens.

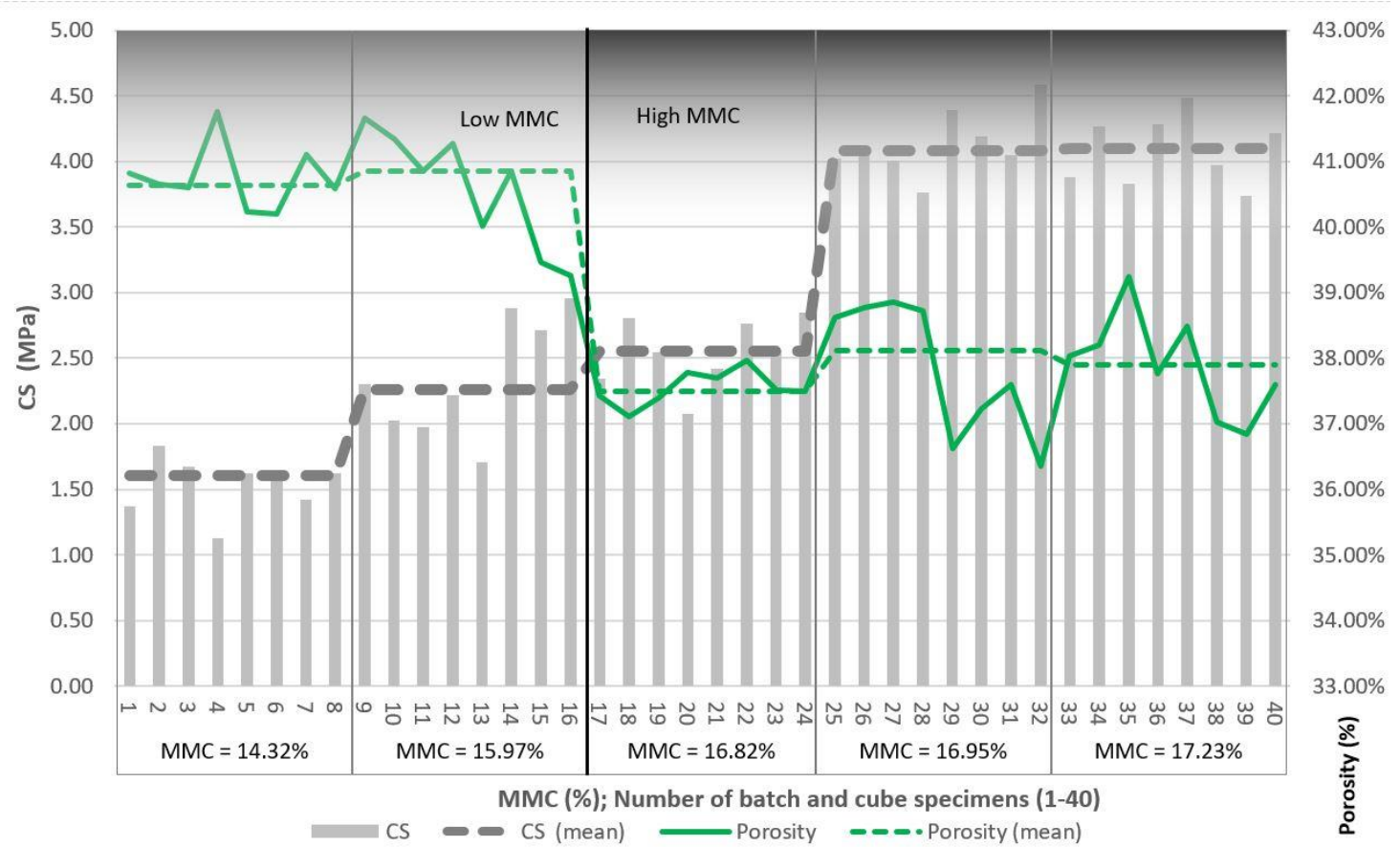

Fig. 9. Representation of $\mathrm{P}$ according to batches and specimens. 
According to Figures 8 and 9, MMC was the variable that always increased with the increase in CS. Therefore, having already presented our arguments in the statistical analysis, the importance of $\mathrm{MMC}$ with respect to physical-mechanical properties may be highlighted. Whenever there was a shortage of moisture (batches 1 and 2 ), in addition to less suction effect, compaction was less efficient for the same specific energy. Thus, for a low MMC (up to $85 \%$ OM), the characteristic values of $D(1.56 \mathrm{~g} / \mathrm{cm} 3)$ decreased up to $7 \%$ and those of $P(40.8 \%)$ were up to $7 \%$ higher than when MMC was considered high ( $90 \%$ of OM, batches 3 to 5). In contrast, a high MMC level was when the maximum values of $C S, D$ and the lowest values of $P$ were reached. However, for batch 3, which presented adequate moisture content and favourable densities and porosities, CS was in a lower range than expected according to batches 4 and 5, but somewhat higher in the dry batches ( 1 and 2). As will be discussed later, UPV for this batch also corresponded to a high CS (approximately $4 \mathrm{MPa}$ ). From the D or P standpoint, there was no obvious explanation for the low CS in batch 3. A construction defect in batch 3 or another uncontrolled parameter (variation in the type of aggregate or distortion of the PSD) may have caused this anomaly. Furthermore, since MMC was not determined by specimen, the authors were unable to establish the exact degree of involvement with the discordances discussed between CS and D-P at individual specimen level.

Likewise, statistics confirmed that ultrasound velocities (X-UPV, Y-UPV, Z-UPV) depended on MMC and that their measurements could be classified according to the low and high MMC groups (low and high MMC corresponded to smaller and larger cluster centres, respectively; see Table 6). In fact, the ultrasound velocities presented in Figures 10 to 12 show good alignment with the MMC levels, with the exception of batch 5 which corresponded to the highest MMC (17.23\%). 


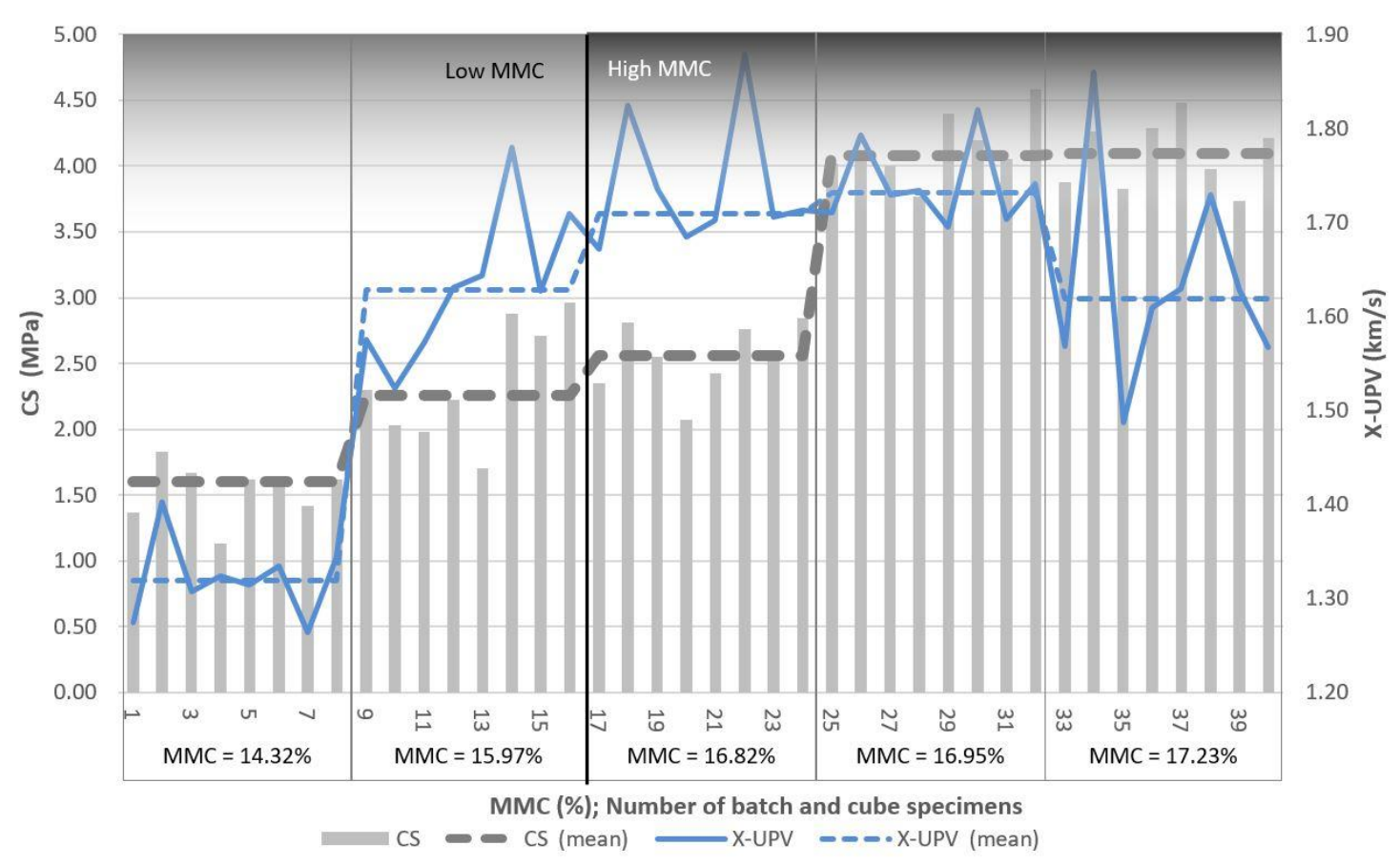

Fig. 10. Representation of X-UPV compared to CS by batches, their mixture moisture content and the specimens.

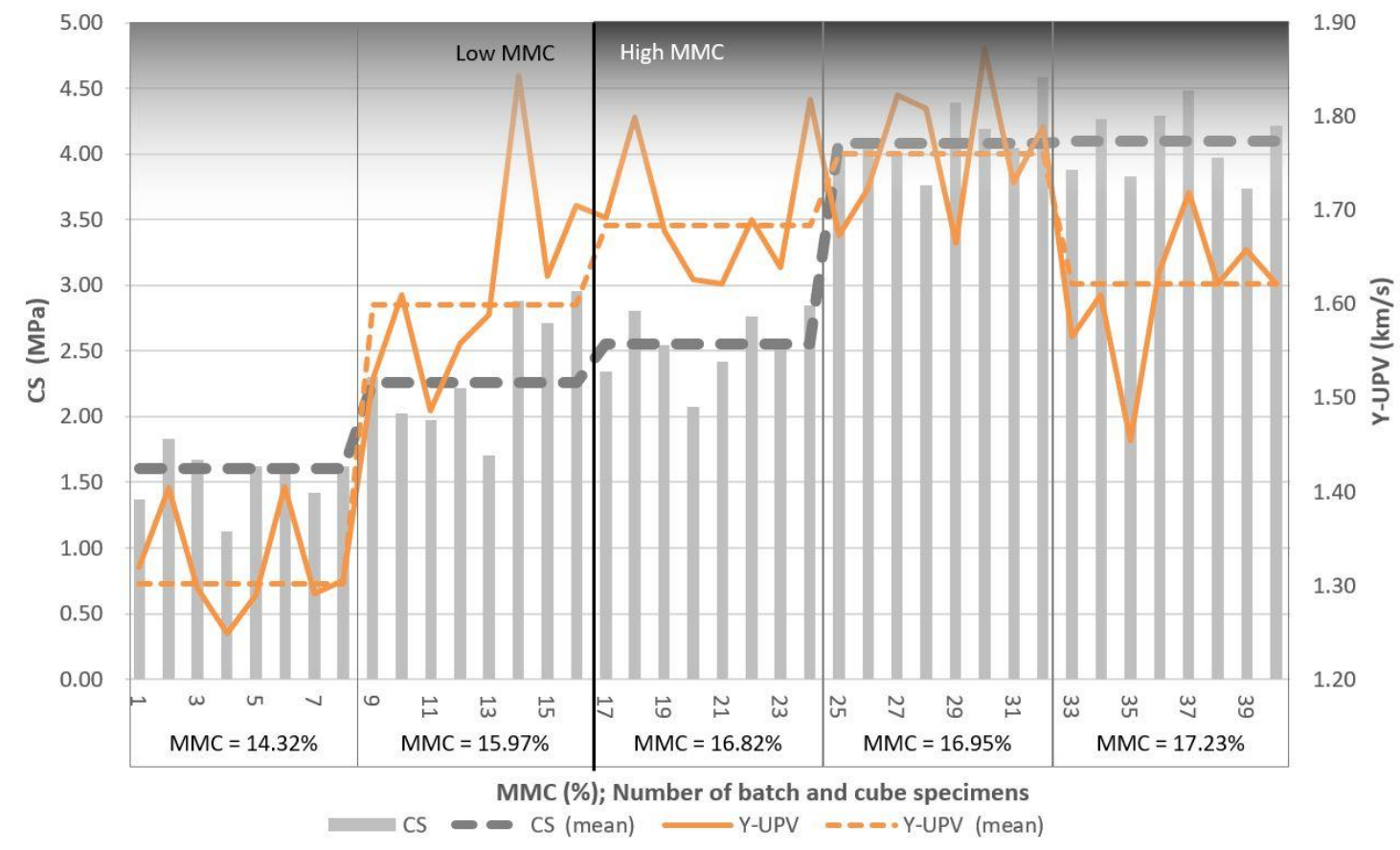

Fig. 11. Representation of Y-UPV compared to CS by batches, their mixture moisture content and the specimens. 


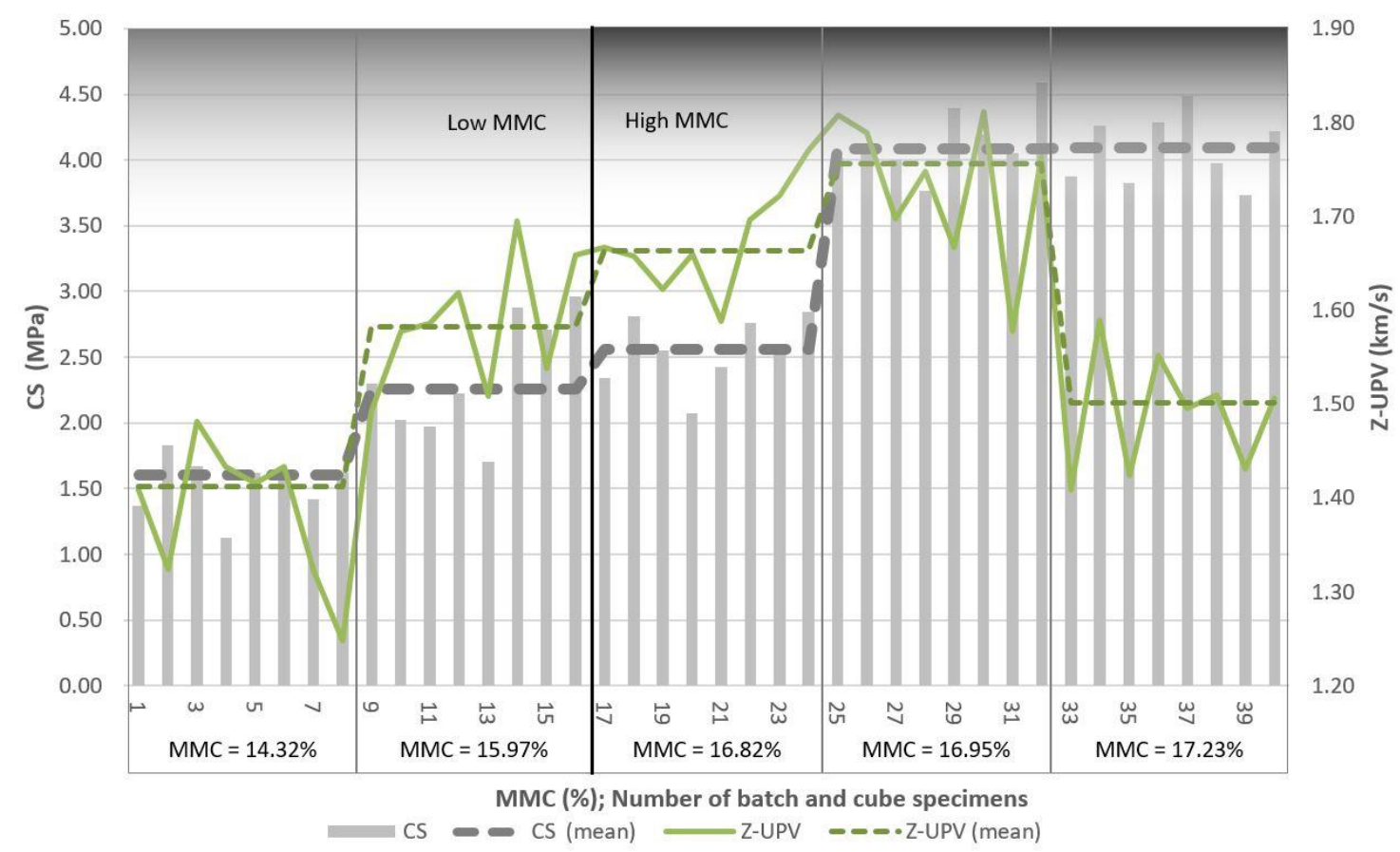

Fig. 12. Representation of Z-UPV compared to CS by batches, their mixture moisture content and the specimens.

With the exception of batch 5 , it is worth highlighting that the medians of Y-UPV and X-UPV maintained a good relationship with CS. In fact, for the abovementioned deficiency in CS of batch 3 (it presented median CS levels lower than the median corresponding to the high MMC group), the ultrasound velocities of batch 3 were also lower than those of batch 4 within the high MMC group, contrasting with $\mathrm{D}$ or $\mathrm{P}$, whose medians remained very similar throughout the high $\mathrm{MMC}$ group. Discarding variations in temperature, shape, D-P and size of the specimens or the length of the ultrasound wave path, the most probable causes of the reduction in UPV in batch 3 were a reduction in the moisture content of the sample or the presence of internal discontinuities.

The behaviour of batch 5 for the three UPVs shows that a higher D or lower $\mathrm{P}$ and a higher CS do not always imply higher ultrasound velocity. The decrease in UPV for batch 5 (MMC $=93 \%$ of $\mathrm{OM})$, which was more pronounced in the $Z$ direction, was in discordance with the behaviour of the previous variables that remained within similar ranges, and can therefore not be explained by a difference in CS, D or P. A small increase of less than $1 \%$ in MMC does not seem significant to explain the reduction, implying that although it was not possible to establish a good 
correlation between UPV and CS by means of multivariate regression, UPV is a parameter that can be used to estimate the quality of a RE wall in terms of its mechanical strength. Knowing that UPV depends on, among other things, MMC and the P of the material [45], it has been demonstrated for other materials with discontinuities or micro cracks that UPV decreases significantly once a critical point of humidity has been reached [44]. This moisture value does not correspond to OM, so the behaviour of UPV will differ from that of $D$ and $P$. This may have been the reason for the reduction in UPV in batch 5, suggesting that the inflection point of MMC for maximum UPV is in the range of $17 \%$, compared to $18.5 \%$ (OM) for maximum D.

\section{Conclusions}

This research analysed the physical-mechanical properties of a RE wall stabilized with lime and their relationship with ultrasounds. The following conclusions may be drawn from the analysis of results:

- The MMC of a RE wall is an important parameter that influences mechanical strength. However, since the mechanical behaviour of this material is largely determined by the manufacturing process employed, controlling $\mathrm{MMC}$ is crucial to ensure uniform results are achieved that allow good quality in the execution of the RE wall. After the application of a statistical methodology, it was demonstrated that $\mathrm{MMC}$ is a parameter that has a decisive influence on $\mathrm{D}, \mathrm{P}$ and $\mathrm{CS}$ variables. Therefore, it is important to establish reliable procedures to measure and control MMC both in the laboratory and on site.

- To summarize, the statistical analyses carried out on the 5 batches of RE specimens allowed the authors to establish two groups, one with MMC under the OM (batches 1 and 2) characterized by low D and CS and high P levels, and another with high MMC with respect $\mathrm{OM}$ (batches 3,4 and 5 ) that were characterized by high $\mathrm{D}$ and $\mathrm{CS}$ and low $\mathrm{P}$ levels. This behaviour may be explained by the fact that when MMC is inadequate, in 
addition to the smaller suction effect, compaction is less efficient for the same specific energy.

- Ultrasound is a complementary non-destructive technique that can be used to qualitatively compare the quality of execution of a RE wall. It has been found that in general, when the CS, D and P variables progressively increase (decrease in case of P) with increasing MMC in the batches, X-UPV, Y-UPV and Z-UPV also increase. However, the behaviour of batch 5 for UPV showed that higher D or lower P and higher CS levels do not always entail higher ultrasound speed. As a result, the authors were unable to establish a good correlation between UPV and CS by means of multivariate regression.

\section{References}

[1] M.E. Arslan, M. Emiroğlu, A. Yalama, Structural behavior of rammed earth walls under lateral cyclic loading: A comparative experimental study. Construction and Building Materials. 133 (2017) 433-442. DOI: 10.1016/j.conbuildmat.2016.12.093.

[2] L. Miccoli, D. V Oliveira, R.A. Silva, U. Müller, L. Schueremans, Static behaviour of rammed earth: experimental testing and finite element modelling. Mater. Struct. 48 (2015) 34433456. DOI:10.1617/s11527-014-0411-7.

[3] C. Jayasinghe, N. Kamaladasa, Compressive strength characteristics of cement stabilized rammed earth walls. Construction and Building Materials. 21 (2007) 1971-1976. DOI:10.1016/j.conbuildmat.2006.05.049.

[4] K.K.G.K.D. Kariyawasam, C. Jayasinghe, Cement stabilized rammed earth as a sustainable construction material. Construction and Building Materials, 105 (2016) 519-527. DOI:10.1016/j.conbuildmat.2015.12.189.

[5] D. Ciancio, J. Gibbings, Experimental investigation on the compressive strength of cored and molded cement-stabilized rammed earth samples. Construction and Building Materials. 28 (2012) 294-304. DOI:10.1016/j.conbuildmat.2011.08.070.

[6] D. Ciancio, P. Jaquin, P. Walker, Advances on the assessment of soil suitability for rammed earth. Construction and Building Materials. 42 (2013) 40-47. DOI: 10.1016/j.conbuildmat.2012.12.049

[7] C.G. da Rocha, N.C. Consoli, A.D. Rosa Johann, C.G. da Rocha, N.C. Consoli, A.D.R. Johann, Greening stabilized rammed earth: devising more sustainable dosages based on strength controlling equations, J. Clean. Prod. 66 (2014) 12-26. DOI: 10.1016/j.jclepro.2013.11.041.

[8] UNE-103-500-94, UNE 103-500-94: Geotechnic. Compaction test. Standard Proctor, 1994.

[9] P.A. Jaquin, C.E. Augarde, D. Gallipoli, D.G. Toll, The strength of unstabilised rammed 
earth materials. Géotechnique. 59 (2009) 487-490. DOI:10.1680/geot.2007.00129.

[10] Q.B. Bui, J.C. Morel, S. Hans, P. Walker, Effect of moisture content on the mechanical characteristics of rammed earth, Construction and Building Materials. 54 (2014) 163169. DOI:10.1016/j.conbuildmat.2013.12.067.

[11] F. Champiré, A. Fabbri, J.C. Morel, H. Wong, F. McGregor, Impact of relative humidity on the mechanical behavior of compacted earth as a building material, Construction and Building Materials. 110 (2016) 70-78. DOI:10.1016/j.conbuildmat.2016.01.027.

[12] E. Baglioni, F. Fratini, L. Rovero, The materials utilised in the erathen buildings sited in the Drâa Valley (Morocco): Mineralogical an mechanical characteristics, in: IX Semin. Iberoam. Construcción Con Tierra ( $9^{\circ}$ SIACOT), VI Semin. Arquit. Terra Em Port. (6 ${ }^{\circ}$ ATP), Coimbra, 2010.

[13] R. Liang, G. Hota, Y. Lei, Y. Li, D. Stanislawski, Y. Jiang, Nondestructive evaluation of historic hakka rammed earth structures, Sustainability. 5 (2013) 298-315. DOI:10.3390/su5010298.

[14] C. Galán-Marín, C. Rivera-Gómez, F. Bradley, Rivera-G\&\#xf3, C. Mez, F. Bradley, Ultrasonic, Molecular and Mechanical Testing Diagnostics in Natural Fibre Reinforced, Polymer-Stabilized Earth Blocks, International Journal of Polymer Science. 2013 (2013) 1-10. DOI:10.1155/2013/130582.

[15] M. Ben Mansour, E. Ogam, Z.E.A. Fellah, A. Soukaina Cherif, A. Jelidi, S. Ben Jabrallah, Characterization of compressed earth blocks using low frequency guided acoustic waves, J. Acoust. Soc. Am. 139 (2016) 2551-2560. DOI:10.1121/1.4948573.

[16] E. Bernat-Maso, E. Teneva, C. Escrig, L. Gil, Ultrasound transmission method to assess raw earthen materials, Construction and Building Materials. 156 (2017) 555-564. DOI:10.1016/j.conbuildmat.2017.09.012.

[17] UNE-EN: 12504-4, UNE-EN: 12504-4: Testing concrete. Part 4: Determination of ultrasonic pulse velocity, España, 2004.

[18] M. Hall, Y. Djerbib, Rammed earth sample production: Context, recommendations and consistency, Construction and Building Materials. 18 (2004) 281-286. DOI:10.1016/j.conbuildmat.2003.11.001.

[19] Q.-B. Bui, J.-C. Morel, S. Hans, N. Meunier, Compression behaviour of non-industrial materials in civil engineering by three scale experiments: the case of rammed earth, Mater. Struct. 42 (2008) 1101-1116. DOI:10.1617/s11527-008-9446-y.

[20] Q.B. Bui, J.C. Morel, Assessing the anisotropy of rammed earth, Construction and Building Materials. 23 (2009) 3005-3011. DOI:10.1016/j.conbuildmat.2009.04.011.

[21] E. Bernat-Maso, L. Gil, C. Escrig, Textile-reinforced rammed earth: Experimental characterisation of flexural strength and thoughness, 106 (2016) 470-479. DOI:10.1016/j.conbuildmat.2015.12.139.

[22] D. Ciancio, C.T.S. Beckett, J.A.H. Carraro, Optimum lime content identification for limestabilised rammed earth, Construction and Building Materials. 53 (2014) 59-65. DOI:10.1016/j.conbuildmat.2013.11.077.

[23] J. Smith, C.C. Augarde, Optimum water content tests for earthen construction materials, Constr. Mater. Proc. Inst. Civ. Eng. (2014). DOI:10.1680/coma.12.00040.

[24] Q.B. Bui, J.C. Morel, S. Hans, P. Walker, Effect of moisture content on the mechanical characteristics of rammed earth, Construction and Building Materials. 54 (2014) 163- 
169. DOI:10.1016/j.conbuildmat.2013.12.067.

[25] C.M. Martins Neves, O. Faria, R. Rotondaro, P. Cevallos, M. Hoffman, Selección de suelos y métodos de control en la construcción con tierra, Proterra-Cyted, 2009. http://www.redproterra.org.

[26] UNE-EN 933-1-12. Tests for geometrical properties of aggregates. Part 1: Determination of particle size distribution - Sieving method, 1998.

[27] UNE 103-103-94. Determination of the liquid limit of a soil by the Casagrande apparatus method (Determinación del límite líquido de un suelo por el método del aparato de Casagrande), Spain, 1994.

[28] UNE 103-104-93. Test for plastic limit of a soil (Determinación del límite plástico de un suelo), Spain, 1993.

[29] A. Walkley, C.A. Black, An examination of the Degtjareff method for determining soil organic matter and a proposed modification of the chromic acid titration method, Soil Sci. 37 (1934) 29-38.

[30] UNE-EN 13039-2012. Soil improvers and growing media. Determination of organic matter content and ash, Spain, 2012.

[31] NZS 4298, NZS 4298 (1998): Materials and workmanship for earth buildings, 4298 (1998) 91.

[32] P. Walker, R. Keable, J. Martin, V. Maniatidis, Rammed Earth. Design and construction guidelines, BRE bookshop, Watford, 2005.

[33] UNE-EN-12504-1, Testing concrete in structures - Part 1: Cored specimens - Taking, examining and testing in compression, AENOR. (2009).

[34] UNE-EN-ISO-17892-1, Geotechnical investigation and testing. Laboratory testing of soil. Part 1: Determination of water content, 2015.

[35] UNE 103-300:93, Determination of moisture content of soil by means oven-dried. (Determinación de la humedad de un suelo mediante secado en estufa), Spain, 1993.

[36] UNE-EN-1015-11, Methods of test for mortar for masonry - Part 11: Determination of flexural and compressive strength of hardened mortar, 2000.

[37] UNE-EN-1936:07, Natural stone test methods - Determination of real density and apparent density, and of total and open porosity, 2007.

[38] UNE-EN-12504-4, Testing concrete. Part 4: Determination of ultrasonic pulse velocity, Espa\{ñ $\} a, 2004$.

[39] F.J. Alejandre, Caracterización analítica de un muro de tapial correspondiente al complejo edilicio de carácter monumental de época Almohade, in: la historia recuperada de un barrio de Sevilla. Ed. A. Rodríguez-Azogue, V. Aycart-Luengo, A. Rodríguez, Sevilla, 2007: p. 245.

[40] P. Walker, The Australian Earth building handbook, Standards Australia International, Sydney :, 2001.

[41] L. Selçuk, A. Nar, Prediction of uniaxial compressive strength of intact rocks using ultrasonic pulse velocity and rebound-hammer number, Q. J. Eng. Geol. Hydrogeol. 49 (2016) 67-75. DOI:10.1144/qjegh2014-094.

[42] Y.-C. Lin, Y. Lin, C.-C. Chan, Use of ultrasonic pulse velocity to estimate strength of 
concrete at various ages, Mag. Concr. Res. 68 (2016) 739-749. DOI:10.1680/jmacr.15.00025.

[43] S. Popovics, Effects of uneven moisture distribution on the strength of and wave velocity in concrete, Ultrasonics. 43 (2005) 429-434. DOI:https://doi.org/10.1016/j.ultras.2004.09.007.

[44] A. Tarmian, S. Eshaghi, H. Gholamiyan, The contradictory effect of drying internal checks and moisture changes on the ultrasonic propagation in poplar wood (Populous nigra), J Indian Acad Wood Sci. 7 (2010) 43-48. DOI:I 10.1007/s13196-011-0009-4.

[45] N.C. Consoli, R.A. Quiñonez, L.E. González, R.A. López, Influence of Molding Moisture Content and Porosity / Cement Index on Stiffness, Strength, and Failure Envelopes of Artificially Cemented Fine-Grained Soils, J. Mater. Civ. Eng. 29 (2017) 1-10. DOI:10.1061/(ASCE)MT.1943-5533.0001819. 